\title{
"A Química das Cores": uma oficina temática para o ensino e aprendizagem de Química
}

"The Chemistry of Colors": a thematic workshop for teaching and learning of Chemistry

Ângela Renata Kraisig e Mara Elisa Fortes Braibante

Universidade Federal de Santa Maria

akraisig@yahoo.com.br;maraefb@gmail.com

\begin{abstract}
Resumo
Neste trabalho, apresentamos a oficina temática "A Química das Cores", desenvolvida no decorrer de uma pesquisa de mestrado, e aplicada para estudantes da $3^{a}$ série do Ensino Médio, de uma escola pública de Santa Maria/RS. A oficina temática foi a metodologia de ensino escolhida para a abordagem dos conhecimentos científicos relacionados à temática cores e, desta forma, buscou-se favorecer o processo de ensino e aprendizagem. Os resultados obtidos nessa pesquisa apontam que a metodologia de ensino desenvolvida auxiliou a construção dos conhecimentos cientificos por parte dos estudantes sobre luz, espectro eletromagnético, presença de cor em soluções iônicas, entre outros.
\end{abstract}

Palavras-chave: Oficina temática, cores, química.

\section{Abstract}

In this paper, we present the thematic workshop "The Chemistry of Colors", developed during a master degree research, and applied to students of the 3rd grade of high school, from a public school in Santa Maria/RS. The thematic workshop was the teaching methodology chosen to approach the scientific knowledge related to the theme colors. In this way, we intend to favor the process of teaching and learning. The results obtained in this research show that the teaching methodology developed helped the students to construct the scientific knowledge about light, electromagnetic spectrum, presence of color in ionic solutions, among others.

Keywords: Thematic workshops, colors, chemistry. 


\section{Introdução}

As aulas de Química ainda são desenvolvidas, em muitas escolas, por meio de atividades em que a parte conceitual é abordada por intermédio da repetição, fragmentação e esvaziamento do caráter social, tornando desinteressante o aprendizado e contribuindo muito pouco para a formação de um cidadão crítico e atuante na sociedade em que vive (MALDANER e SANTOS, 2010). Além disso, leva muitos estudantes a considerar, a disciplina de Química difícil, abstrata e sem relação com o seu cotidiano. Desta maneira, acredita-se que seja de fundamental importância que o professor busque utilizar em suas aulas diferentes metodologias de ensino, capazes de despertar nos estudantes o gosto pela Química, de maneira que consigam compreender e relacionar os conhecimentos científicos com o seu cotidiano.

Neste trabalho, a metodologia de ensino que utilizamos e iremos relatar foi uma oficina temática. Conforme Pazinato (2012), a palavra oficina remete a ideia de "casa ou local de trabalho" e a expressão temática se refere a um "assunto ou matéria", unindo ambos os significados, conduz a ideia de "um local que se trabalha algum assunto". No caso deste trabalho, o assunto é a temática cores, sendo que a partir dela desenvolvemos a oficina temática intitulada: "A Química das Cores", para abordar conceitos científicos relacionados à Ciência, com ênfase em Química.

Conforme Marcondes (2008) e Silva et al., (2014), as oficinas temáticas procuram tratar os conhecimentos de forma inter-relacionada e contextualizada, envolvendo os estudantes em um processo ativo na construção de seu próprio conhecimento. Neste sentido, de forma resumida, as principais características das oficinas temáticas são:

\footnotetext{
- Utilização da vivência dos alunos e dos fatos do dia a dia para organizar o conhecimento e promover aprendizagens;

- Abordagem dos conteúdos de Química a partir de temas relevantes que permitam a contextualização do conhecimento;

- Estabelecimento de ligações entre a Química e outros campos do conhecimento necessários para se lidar com o tema em estudo;

- Participação ativa do estudante na elaboração do seu conhecimento (SILVA et al., 2014, p. 483).
}

Portanto, para o desenvolvimento de uma oficina temática, dois princípios são fundamentais: a contextualização e a experimentação (Figura 1).

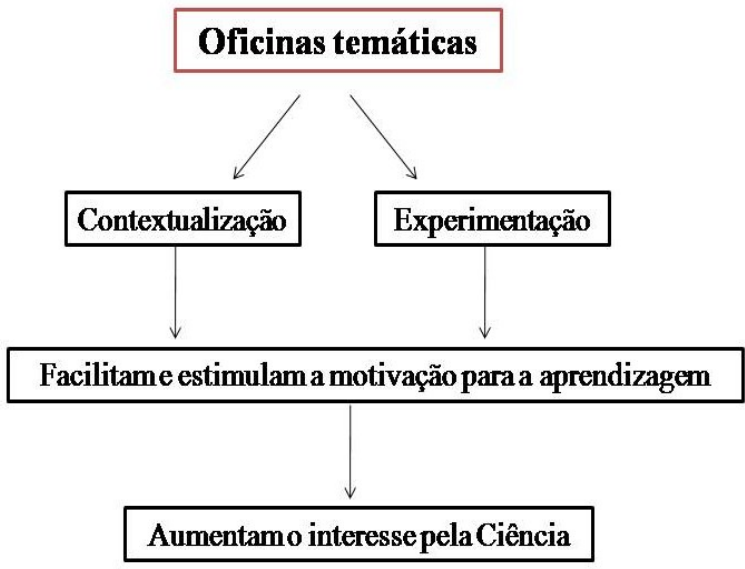

Figura 1- Princípios das oficinas temáticas

Fonte: (SILVA et al., 2014) 
O tema escolhido para a abordagem em uma oficina temática deve permitir a contextualização do conhecimento científico e as atividades experimentais devem ter um caráter predominantemente investigativo, de forma que desenvolvam a curiosidade e permitam ao aluno testar e aprimorar suas ideias. Os conceitos escolhidos devem ser desenvolvidos em um nível de aprofundamento suficiente para o entendimento das situações em estudo e proporcionar uma aprendizagem significativa (PAZINATO e BRAIBANTE, 2014).

De acordo com Braibante e Pazinato (2014), a utilização de oficinas temáticas no ensino proporciona maior participação dos estudantes na elaboração do seu conhecimento, momentos de discussão e trocas entre professor e aluno e entre os próprios alunos e aplicação dos conceitos em fatos do seu cotidiano, o que geralmente torna o processo de ensino e aprendizagem mais prazeroso e significativo para os estudantes.

As oficinas temáticas, quando utilizadas no ensino, podem ser estruturadas nos três momentos pedagógicos descritos por Delizoicov, Angotti e Pernambuco (2009): Problematização Inicial (PI), Organização do Conhecimento (OC) e Aplicação do Conhecimento (AC). No primeiro momento pedagógico (PI), os estudantes são desafiados a expor o que pensam. Dessa forma, é realizado um levantamento das concepções iniciais dos estudantes sobre o tema em questão, sendo que o principal objetivo é problematizar. No segundo momento pedagógico (OC), os conhecimentos selecionados como necessários para a compreensão dos temas e da problematização inicial são sistematicamente estudados nesse momento, sob a orientação do professor. O terceiro momento (AC), sugere a reinterpretação do problema inicial, tendo como base os conhecimentos adquiridos na (OC), várias atividades podem ser desenvolvidas neste momento para que os estudantes estejam aptos a aplicar os conhecimentos adquiridos.

Neste trabalho, iremos apresentar a oficina temática, denominada: "A Química das Cores", desenvolvida em uma pesquisa de mestrado (KRAISIG, 2016), bem como analisar as suas implicações na construção dos conhecimentos científicos por parte dos estudantes.

\section{Contexto da oficina temática}

A oficina temática "A Química das Cores", foi desenvolvida em duas turmas de $3^{\text {a }}$ série do Ensino Médio, do noturno de uma escola estadual localizada em Santa Maria/RS. As duas turmas eram compostas por 29 estudantes, sendo que no total, 23 deles participaram do início ao fim da oficina temática.

No decorrer da oficina temática, os sujeitos participantes, responderam questionários (inicial e final), realizaram atividades descritivas e de ilustração. Neste trabalho, serão apresentados e analisados os dados obtidos nos questionários, uma vez que os mesmos permitem indicar se a oficina temática contribuiu para a construção do conhecimento.

\section{Desenvolvimento da oficina temática "A Química das Cores"}

A oficina temática em questão foi elaborada conforme os pressupostos teóricos dos três momentos pedagógicos, descritos por Delizoicov, Angotti e Pernambuco (2009). Os objetivos da oficina temática foram: Relacionar a temática Cores com o cotidiano dos estudantes, abordar o experimento de Newton sobre as cores, relacionar a presença de luz com as cores, compreender como ocorre a percepção das cores, auxiliar os estudantes na interpretação do espectro eletromagnético e do disco de cores, abordar a presença das cores em corantes orgânicos, 
entender por que os elementos químicos do bloco $d$ da tabela periódica apresentam ou não cor e, por fim, realizar experimentos para auxiliar na compreensão dos diversos conteúdos abordados na oficina.

A seguir, será apresentado no Quadro 1 uma síntese das atividades desenvolvidas nos diferentes momentos da oficina temática.

Quadro 1 - Síntese das atividades desenvolvidas na oficina temática

\begin{tabular}{|c|c|}
\hline $1^{\circ}$ momento: Problematização inicial & $\begin{array}{l}\text { - Questionário inicial. } \\
\text { - Problematização sobre a presença das cores no cotidiano. } \\
\text { - Atividade experimental: "Decomposição da luz branca". }\end{array}$ \\
\hline $2^{\circ}$ momento: Organização do conhecimento & - Abordagem dos conteúdos. \\
\hline $3^{\circ}$ momento: Aplicação do conhecimento & $\begin{array}{l}\text { - Atividades experimentais: "Investigando a Química presente nas Cores". } \\
\text { - Questionário final. }\end{array}$ \\
\hline
\end{tabular}

\section{$1^{\circ}$ momento pedagógico - Problematização inicial:}

Inicialmente, com o objetivo de conhecer as concepções prévias dos estudantes, aplicou-se um questionário investigativo, contendo questões relacionadas à temática cores como: luz, espectro eletromagnético (comprimento de onda, frequência, energia) e soluções, conforme o Quadro 2.

\section{Quadro 2 - Questões do questionário inicial}

1) “Epícuro, há mais de 2.300 anos desenvolveu o raciocínio de que a cor guarda íntima relação com a luz”. De acordo com esta afirmativa, assinale a alternativa que você considera correta e justifique a sua escolha.

(a) A cor só é visualizada quando falta luz.

(b) Cor e luz apresentam grande relação, sendo que quando falta luz não enxergamos as cores.

(c) As cores que visualizamos nos objetos independem da presença de luz.

(d) Cor e luz apresentam uma íntima relação, sendo que na ausência de luz não enxergamos nem tonalidades de cinza.

(e) A luz é essencial para o objeto não aparecer colorido.

Justificativa:

2) Observe a imagem a seguir:

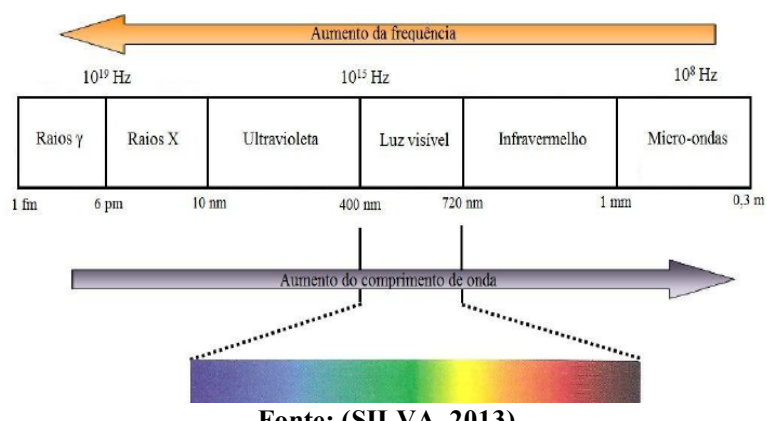

a) O que você acha que está representado na imagem?

Fonte: (SILVA, 2013).

b) Na sua opinião essa imagem apresenta alguma relação com o tema "Cores”. Justifique.

c) $\mathrm{O}$ que você acha que representa o comprimento de onda, a energia e a frequência nessa imagem?

3) A solução de $\mathrm{Ni}\left(\mathrm{NO}_{3}\right)_{2}$ apresenta coloração verde. Em sua opinião, qual é a explicação química sobre a presença de cor nessa solução? 
Em seguida, com o auxílio do projetor multimídia, apresentou-se slides com imagens coloridas para o desenvolvimento da problematização inicial. Nesse momento, ocorreram discussões sobre a presença da cor no nosso cotidiano, como por exemplo: nos objetos, na natureza, na Química entre outros (Figura 2).

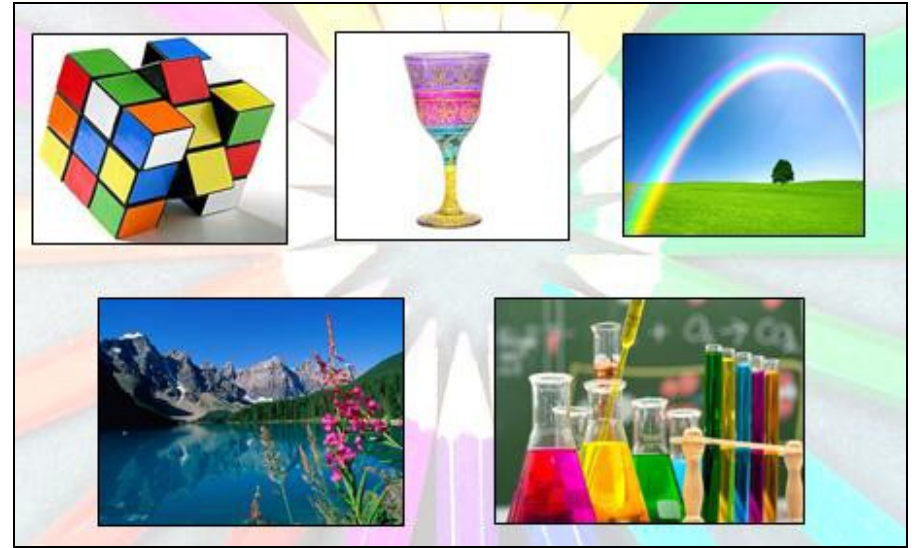

Figura 2- Slide apresentado na problematização inicial

Ainda no primeiro momento, os estudantes realizaram à primeira atividade experimental, denominada: "Decomposição da luz branca", em que utilizaram um prisma de vidro óptico e um espectroscópio caseiro (Figura 3). Para a realização dessa atividade experimental a presença de luz foi indispensável, para a visualização das cores.

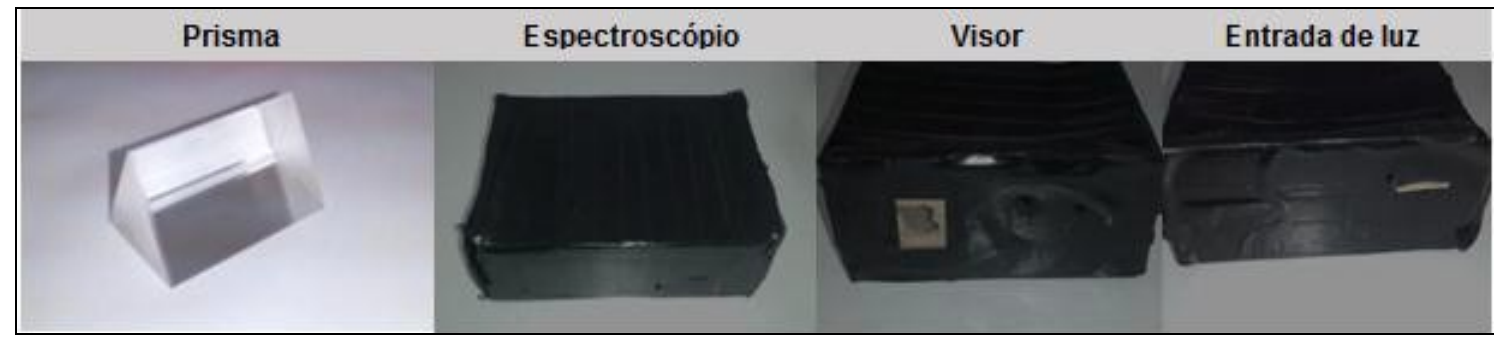

Figura 3 - Prisma de vidro óptico e espectroscópio caseiro

A prática experimental, "Decomposição da luz branca", consistia em direcionar cada um dos equipamentos, prisma e espectroscópio sobre uma lâmpada fluorescente e observar as diferentes cores formadas. Nessa atividade os estudantes deveriam anotar a ordem das cores que visualizaram com os dois equipamentos para, posteriormente, elaborar o seu disco de cores.

A ideia da elaboração do disco de cores foi para permitir uma melhor compreensão dos assuntos que seriam abordados na organização do conhecimento, considerando que cada cor varia com o comprimento de onda, frequência e energia.

\section{$2^{\circ}$ Momento Pedagógico - Organização do conhecimento}

Nesse momento, foram apresentados alguns tópicos necessários para o entendimento da temática cores no ensino de Química. Para isso, foi necessário explicar conceitos que envolvem as disciplinas de Biologia e Física. Dessa forma os conteúdos abordados foram: Experimento de Newton sobre as cores, relação entre a luz e a visão, células fotorreceptoras presentes no olho humano, espectro eletromagnético e a relação entre comprimento de onda, frequência e energia, disco de cores (ligação entre cor absorvida e cor refletida), corantes orgânicos: compreensão de cromóforos e 
auxocromos, diagrama de níveis de energia e, por fim, tabela periódica especificamente os elementos químicos do bloco d. Foi disponibilizado aos estudantes um material de apoio, elaborado pelos pesquisadores, contendo os conteúdos abordados, que serviu como fonte de pesquisa durante a aplicação da oficina.

\section{$3^{\circ}$ momento pedagógico - aplicação do conhecimento}

A aplicação do conhecimento ocorreu em duas etapas. Inicialmente foram propostas duas atividades experimentais de caráter investigativo, intituladas: "Investigando a Química presente nas Cores". Para o desenvolvimento destas atividades, cada turma foi dividida em dois grupos.

Para a realização da primeira atividade experimental, foi confeccionado um equipamento para a visualização das cores, utilizando alguns materiais de fácil acesso presentes no nosso cotidiano, tais como: caixa de sapato, isopor, CD e fita adesiva. A construção desse instrumento consistia em fazer duas fendas paralelas, uma maior (abaixo) e outra menor (acima) em uma das laterais menores da caixa de sapato. O isopor foi utilizado para fixar o CD no interior da caixa, sendo que a parte gravável deve estar voltada para as fendas (Figura 4).

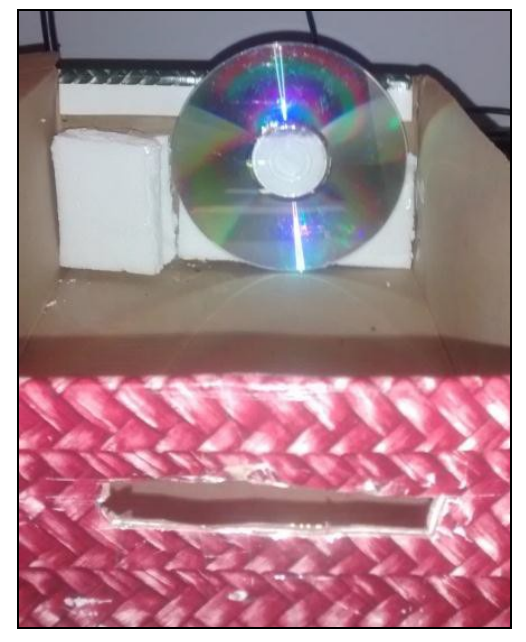

Figura 4 - Instrumento utilizado na primeira atividade experimental

Desta forma, com o objetivo de abordar alguns conhecimentos de Química, foram selecionadas algumas amostras de soluções coloridas de íons de metais de transição, $\mathrm{Ni}^{2+}$ verde, $\mathrm{Cu}^{2+}$ azul, $\mathrm{Co}^{2+}$ vermelho e também solução incolor de $\mathrm{Zn}^{2+}$ para serem testadas no equipamento.

Nessa atividade, os estudantes colocaram no interior do equipamento confeccionado, uma amostra de cada vez, entre as fendas e o CD e inseriram a lanterna na fenda inferior, fazendo com que a luz branca incidisse sobre a amostra. Através da fenda superior eles conseguiram verificar no CD a cor que mais se destacou, como por exemplo, a amostra de coloração vermelha apresentou no $\mathrm{CD}$ várias cores, porém a cor que mais se destacou foi a verde, referente aos comprimentos de onda que foram absorvidos pela amostra, ou seja, a cor complementar. A Figura 5 apresenta os materiais e as amostras utilizadas nesse experimento.

O objetivo da atividade experimental realizada foi averiguar se os estudantes haviam compreendido o disco de cores (relação entre cor absorvida versus cor complementar) e a presença de cor em soluções dos metais de transição, sendo que esses assuntos foram abordados no segundo momento da oficina. Dessa forma, nesse momento os estudantes puderam aplicar os conhecimentos adquiridos. 


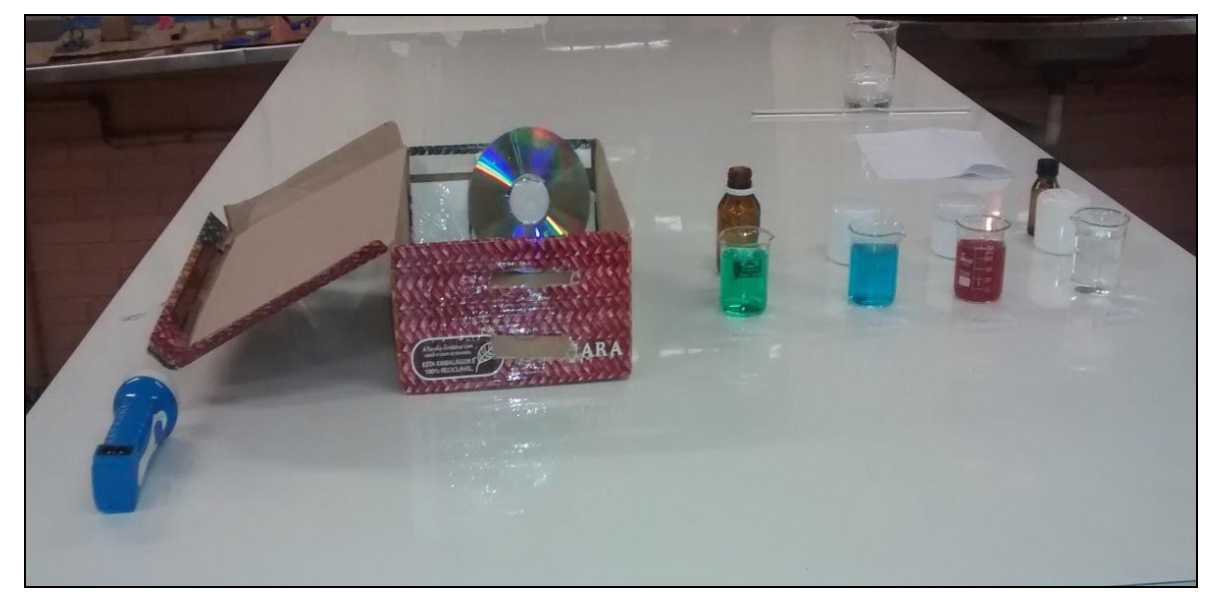

Figura 5 - Materiais e amostras utilizadas no primeiro experimento

Na segunda atividade experimental dessa oficina, os estudantes utilizaram 6 amostras de corantes alimentícios vermelho e verde, que foram preparadas, utilizando béqueres de $50 \mathrm{~mL}$ para adicionar $30 \mathrm{~mL}$ de água em cada um deles. Os corantes foram adicionados em cada béquer em diferentes quantidades (Quadro 3). Além disso, também foi necessário raios lasers de feixes de luz vermelho e verde.

Quadro 3 - Número de amostras e de gotas dos corantes utilizados

\begin{tabular}{|c|c|}
\hline Número de amostras de cada corante & Número de gotas de cada corante \\
\hline 1 & 1 \\
\hline 2 & 3 \\
\hline 3 & 6 \\
\hline 4 & 9 \\
\hline 5 & 12 \\
\hline 6 & 15 \\
\hline
\end{tabular}

Para a realização dessa prática experimental, os estudantes direcionaram os feixes de luz dos lasers vermelho e verde nas diferentes amostras de corantes. Essa prática permitiu a visualização da absorção seletiva, ou seja: corante de cor vermelha absorve somente os comprimentos de onda da luz do laser verde, ou seja, da sua cor complementar e verificaram que o oposto ocorre com o corante de cor verde. A Figura 6 apresenta a realização da segunda atividade experimental pelos estudantes.

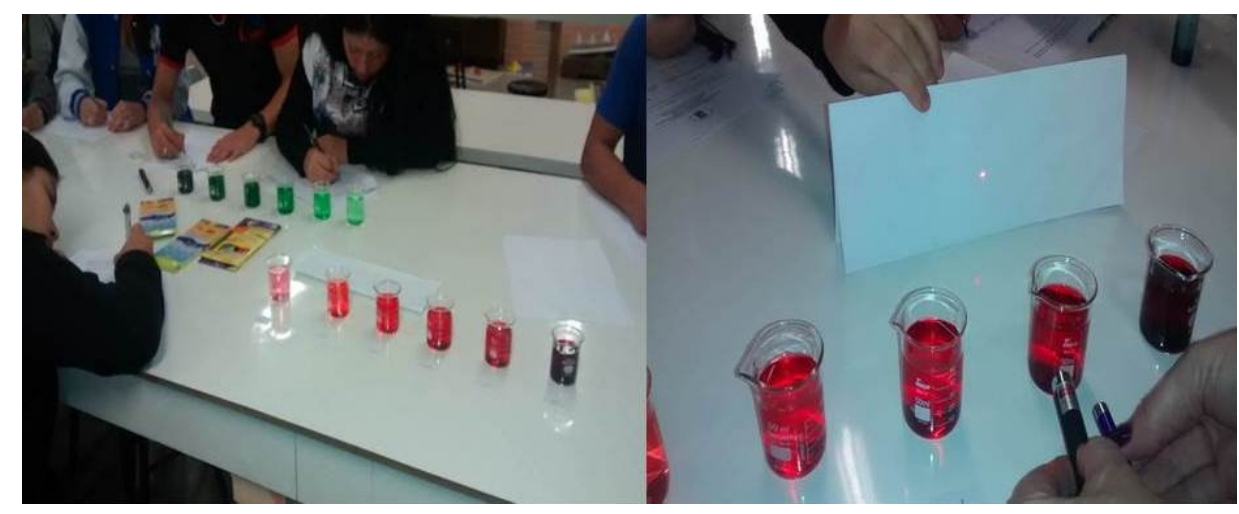

Figura 6 - Segunda atividade experimental 
O objetivo dessa atividade foi verificar se os estudantes conseguiam relacionar a prática experimental com os assuntos estudados no segundo momento, constituindo assim, a aplicação do conhecimento.

As duas atividades experimentais realizadas nesse momento apresentam características de atividades investigativas (OLIVEIRA, 2010), pelo fato que os estudantes receberam os instrumentos, vidrarias e amostras para realizar as atividades e não seguiram nenhum roteiro pronto. Nessas atividades os estudantes, realizaram testes, propuseram hipóteses, participaram de forma ativa e discutiram os resultados encontrados.

Na perspectiva de Suart e Marcondes (2008) as atividades de caráter investigativo permitem aos estudantes:

Que estes construam suas explicações para a compreensão do fenômeno, estabelecendo relações entre os dados e fatos químicos observados. Pode-se oferecer ao aluno a oportunidade de pensar sobre o problema, resolvê-lo através da experimentação, relatar e discutir suas ideias, que poderão contribuir para o processo de conceituação do fenômeno químico (SUART; MARCONDES, 2008, p.2).

Na segunda etapa da aplicação do conhecimento, os estudantes responderam a um questionário investigativo, semelhante ao aplicado no início da oficina, relacionado aos assuntos abordados durante as intervenções (Quadro 4).

Quadro 4- Questões do questionário final

1)Questão idêntica a do questionário inicial.

2)Observe a imagem a seguir:

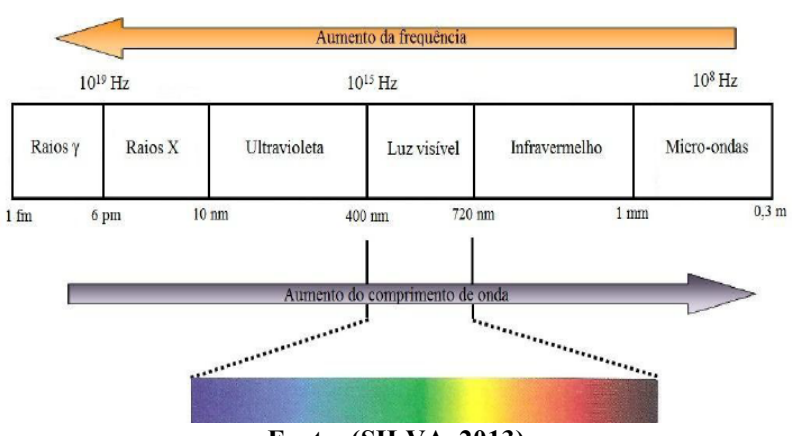

Fonte: (SILVA, 2013).

a) O que você acha que está representado na imagem?

b) Na sua opinião essa imagem apresenta alguma relação com o tema "Cores". Justifique.

c) Explique a região da luz visível em termos de comprimento de onda, energia e frequência.

Sendo que $\mathrm{E}=\mathrm{h}$. $\mathrm{v}$ e $\mathrm{v}=\mathrm{c} / \lambda$

$\mathrm{E}=$ energia, $\mathrm{h}=$ constante de Plank, $\mathrm{v}=$ frequência, $\mathrm{c}=$ velocidade da luz e $\lambda=$ comprimento de onda.

3) Algumas soluções que apresentam metais de transição são geralmente coloridos. Isso sugere que os elétrons presentes nos orbitais $d$ que estão parcialmente preenchidos devem estar envolvidos no fenômeno da geração da cor. Qual das configurações eletrônicas melhor representa este fenômeno:
(a) $1 \mathrm{~s}^{2} 2 \mathrm{~s}^{2} 2 \mathrm{p}^{6} 3 \mathrm{~s}^{2} 3 \mathrm{p}^{6} 3 \mathrm{~d}^{7}$
(b) $1 \mathrm{~s}^{2} 2 \mathrm{~s}^{2} 2 \mathrm{p}^{6} 3 \mathrm{~s}^{2} 3 \mathrm{p}^{6} 3 \mathrm{~d}^{10}$
(c) $1 \mathrm{~s}^{2} 2 \mathrm{~s}^{2} 2 \mathrm{p}^{6} 3 \mathrm{~s}^{2} 3 \mathrm{p}^{6}$
(d) $1 \mathrm{~s}^{2} 2 \mathrm{~s}^{2} 2 \mathrm{p}^{6} 3 \mathrm{~s}^{2} 3 \mathrm{p}^{5}$
(e) $1 s^{2} 2 s^{2} 2 p^{6} 3 s^{2} 3 p^{6} 3 d^{0}$
Justifique: 
Essa oficina foi realizada em encontros quinzenais na escola e foi desenvolvida nos períodos da disciplina de química de cada turma. Foram necessárias 6 horas/aula para a sua realização, totalizando três dias diferentes de intervenção.

\section{Resultados e discussões}

Os questionários investigativos foram analisados por meio da Análise Textual Discursiva (ATD), que de acordo com Moraes e Galiazzi (2006) é uma análise de dados que transita entre duas formas de análise na pesquisa qualitativa: a análise de conteúdo e a análise de discurso. Para a realização da análise textual discursiva (ATD), foram consideradas as etapas propostas por Moraes (2003). Na primeira etapa foi realizada a desconstrução e unitarização, que envolve a desmontagem de textos, para realizar de forma detalhada a análise dos dados. Na segunda etapa, foram elaboradas as categorias que emergiram a partir da unidade - conhecimento científico sobre cores - estabelecida na primeira etapa. Na última etapa, foi realizada a interpretação das categorias por meio de uma visão crítica do todo.

Com isso, as categorias elaboradas com base na análise dos questionários (Quadro 1 e Quadro 2) foram as seguintes:

1) Relação entre cor e luz.

2) Compreensão do espectro eletromagnético.

3) Compreensão da cor em soluções iônicas de metais de transição.

Por meio das três categorias, buscamos analisar os conhecimentos científicos dos estudantes referentes à relação da temática cores e o conhecimento químico, ao início e ao final da oficina temática.

\section{Categoria 1 - Relação entre cor e luz}

No questionário inicial e final, os estudantes foram investigados sobre a relação existente entre a cor e a luz, por meio de uma questão objetiva (Quadro 1). Essa questão, apresentava 5 alternativas, sendo que apenas uma estava correta. Após a escolha da alternativa, os estudantes deveriam justificá-la. A alternativa correta para esta questão objetiva é a letra b que menciona "Quando falta luz não enxergamos as cores".

A Figura 7 representa um gráfico, que corresponde às alternativas escolhidas pelos 23 estudantes no questionário inicial e final sobre a relação existente entre a cor e a luz.

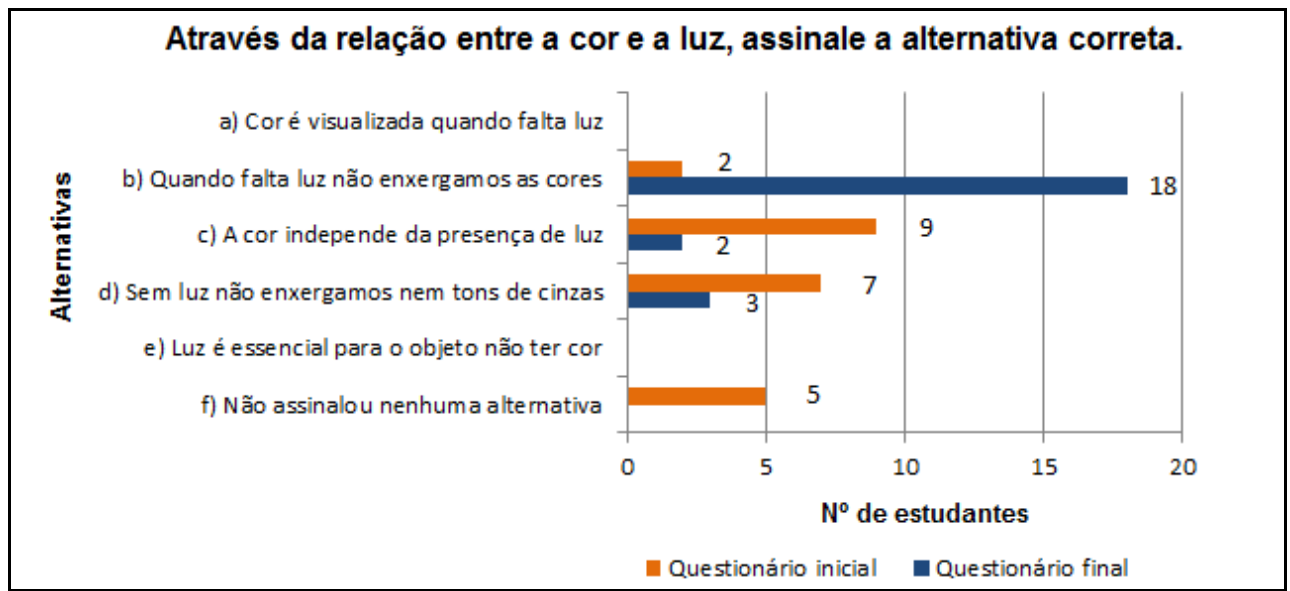

Figura 7 - Número de estudantes e alternativas escolhidas sobre cor e luz 
Em relação ao questionário inicial, identificou-se que os estudantes ficaram confusos na escolha da alternativa, apenas 2, conseguiram interpretar de forma correta a questão. Dentre os 23 estudantes, 16 assinalaram alternativas equivocadas e 5 não assinalaram nenhuma alternativa.

A alternativa que foi escolhida pela maioria dos estudantes no questionário inicial foi a c: "a cor independe da presença de luz". Essa alternativa é incorreta, pois para conseguirmos visualizar as cores, a presença de luz é indispensável, ou seja, ambas apresentam relação intrínseca. Algumas justificativas dos estudantes que escolheram essa alternativa foram:

\section{E2: Sem luz enxergamos as cores.}

\section{E13: Luz não é necessária.}

E20: Independe para ter cor.

E22: Eu não sei certo, mas acho que não precisa luz.

Já com relação à alternativa que destaca "sem luz não enxergamos nem tons de cinzas", assinalada inicialmente por 7 estudantes é incorreta, pois considera que na ausência de luz nem tons de cinzas conseguimos visualizar, porém, é possível. Algumas justificativas dos estudantes foram:

E12: Sim, enxergamos preto.

E15: Acho que não enxergamos.

E19: Enxergamos só o que dá.

E24: Sei lá, acho que não vamos ver nada.

No questionário aplicado ao final da oficina temática, foi possível detectar que a maioria dos estudantes, ou seja, 18 conseguiram assinalar a alternativa correta. Porém, ainda 5 estudantes confundiram e assinalaram alternativas incorretas. Algumas justificativas apresentadas pelos estudantes que assinalaram a alternativa correta foram:

E2: Sem a presença de luz não conseguimos ver e nem saber a cor dos objetos.

E6: Sem luz não conseguimos enxergar as cores.

E13: Que a luz é essencial para enxergarmos as cores, com falta de luz não conseguimos visualizar as cores.

E17: A luz é essencial para o objeto aparecer colorido.

A partir dos resultados obtidos nessa questão, verificamos que ao final da oficina, a maioria dos estudantes conseguiu compreender a relação existente entre as cores que visualizamos e a presença de luz. Desta forma, acreditamos que a oficina temática foi importante, pois possibilitou aos estudantes uma melhor compreensão sobre esse assunto.

\section{Categoria 2 - Compreensão do espectro eletromagnético}

Nesta categoria, analisamos duas questões semelhantes relacionadas ao espectro eletromagnético (Quadro 1 e Quadro 2). A partir das questões, selecionamos cinco itens para análise, que estão representados pelas letras a até e na Figura 8. Os itens analisados partem da identificação do espectro eletromagnético e relação do mesmo com a temática “Cores" até a interpretação do mesmo em relação à frequência, a energia e ao comprimento de onda.

Em relação aos itens: a, b, d e e da questão que envolve a compreensão do espectro eletromagnético, identificamos que os estudantes inicialmente não sabiam a respeito do assunto. Conforme os comentários dos estudantes relacionados a esta questão, a maioria salientou que não haviam estudado sobre o tópico em questão. No questionário inicial, apenas 2 estudantes mencionaram que o espectro eletromagnético estava relacionado com a frequência das cores na região do visível (item c). 
A respeito do item a, presente no questionário final, a maioria dos estudantes conseguiu identificar o espectro eletromagnético. Sendo assim, dos 23 estudantes que responderam os questionários, 20 conseguiram identificar corretamente a imagem que ilustrava o espectro eletromagnético.

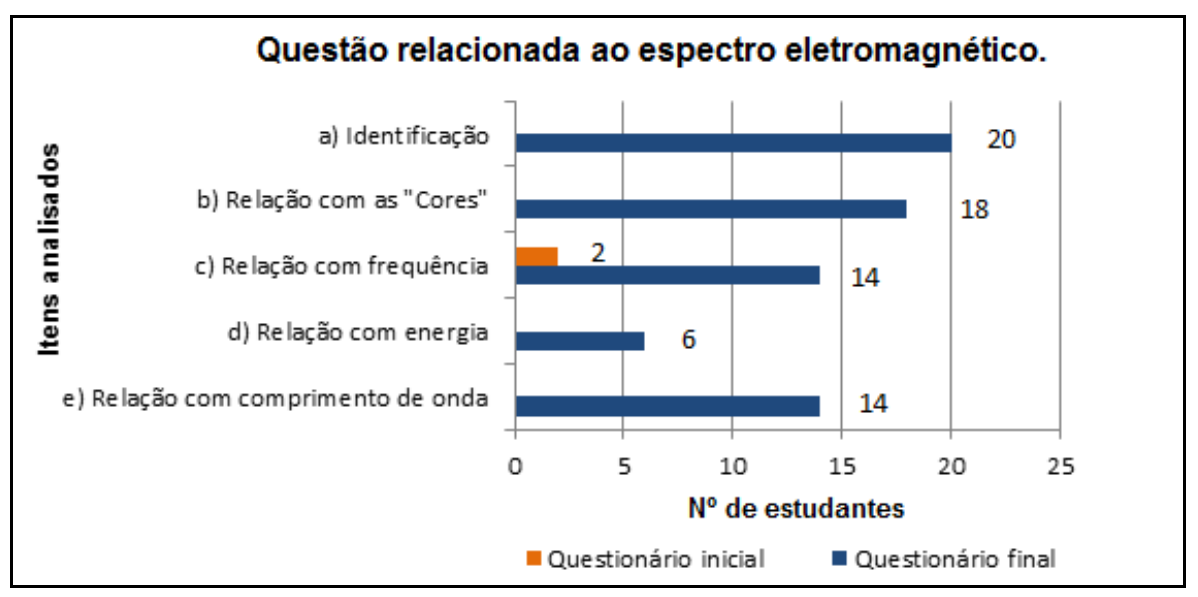

Figura 8 - Número de estudantes e os itens analisados para a questão relacionada ao espectro eletromagnético

Quanto ao item b, que investigava os estudantes sobre a relação existente entre o espectro eletromagnético e as "Cores", dos 23 estudantes, 18 conseguiram fazer relações no questionário final. Algumas respostas dos estudantes foram:

E5: A região da luz visivel é que a gente enxerga.

E10: O espectro eletromagnético representa na região do visível as cores que conseguimos ver, que varia do violeta ao vermelho.

E13: A região de luz visível tem relação com as cores, pois nem antes de $400 \mathrm{~nm}$ e nem depois de $720 \mathrm{~nm}$ podemos enxergar as cores.

E16: No espectro eletromagnético podemos dizer se é possível ver as cores ou não, depende da região.

A partir das respostas apresentadas pelos estudantes, foi possível perceber que os mesmos conseguiram relacionar o espectro eletromagnético com as cores que visualizamos, ou seja, com a região denominada de luz visível.

Com base nos itens $\mathbf{c}, \mathbf{d}$ e e, presentes no questionário final que são referentes respectivamente a frequência, a energia e o comprimento de onda, muitos estudantes tiveram dificuldades em discutir. Um dos itens menos discutido foi o da energia, apenas 6 estudantes a mencionaram em suas respostas, conforme observado a seguir:

E2: Violeta apresenta aumento na frequência e baixo comprimento de onda.

E6: Na cor violeta tem aumento da frequência que é proporcional a energia e diminui o comprimento de onda. Na cor vermelha tem uma diminuição de frequência e energia e aumento do comprimento de onda.

E10: A cor violeta tem baixo comprimento de onda e uma maior frequência comparando com a cor vermelha que é o contrário.

E16: A cor amarela tem energia aumentando e frequência também, porém, comprimento de onda diminuindo em relação a cor vermelha.

Foi possível identificar, através das respostas dos estudantes comparações entre algumas cores presentes na região denominada de luz visível em termos de frequência, comprimento de onda e também energia. A maioria dos estudantes explicou as cores, considerando apenas a frequência e o comprimento de onda, como no caso do E2 e E10 e 
não relataram sobre a energia. Porém, um menor número de estudantes, como E6 e E16 mencionaram a energia em sua explicação.

A compreensão e interpretação do espectro eletromagnético requer entendimento dos itens que foram mencionados acima. No entanto, mesmo após os estudantes participarem da oficina temática, que tratou sobre esse assunto, os mesmos apresentaram dificuldades em interpretar adequadamente o espectro eletromagnético no questionário final. Com isso, acreditamos que um dos motivos que dificultou o entendimento do espectro eletromagnético foi o seu elevado nível de abstração e complexidade do conteúdo.

\section{Categoria 3 - Compreensão da cor em soluções iônicas de metais de transição}

Para esta categoria, analisamos duas questões semelhantes presentes no questionário inicial e final (Quadro 1 e Quadro 2). Na Figura 9, apresentamos no gráfico as justificativas apontadas pelos estudantes, em relação à presença de cor em soluções iônicas de metais de transição.

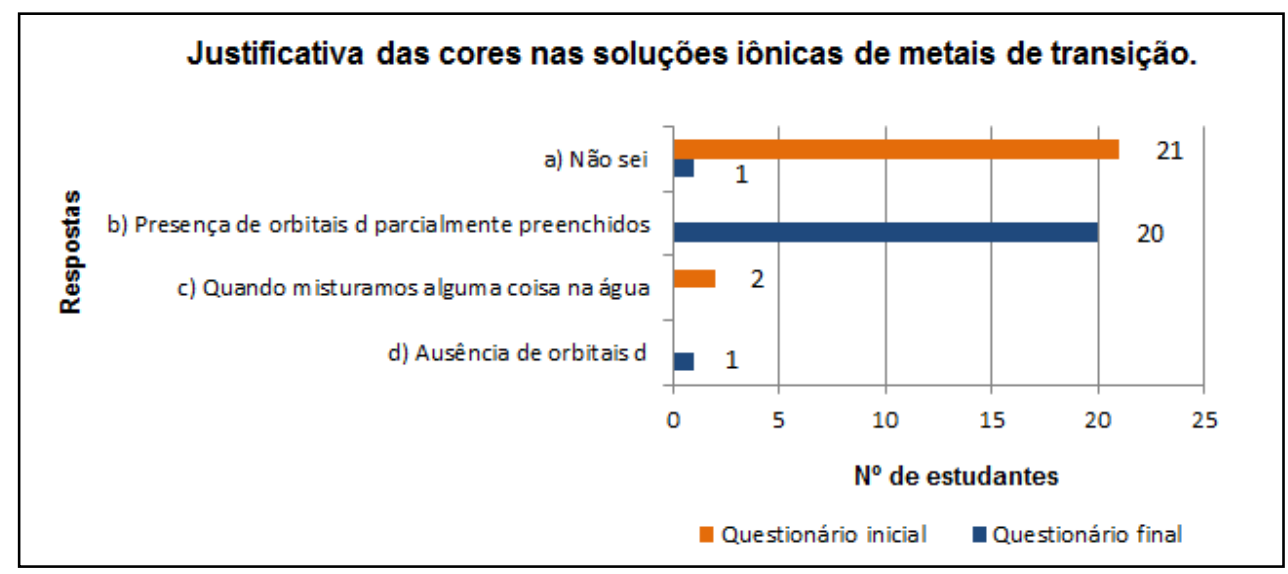

Figura 9 - Número de estudantes e as respostas referentes a questão sobre a presença de cor em soluções

iônicas de metais de transição

No questionário aplicado inicialmente, em que os estudantes foram investigados sobre a presença de cor em soluções iônicas de metais de transição, dos 23 estudantes que responderam, 21 não sabiam justificar o motivo da presença de cor e 2 estudantes mencionaram que:

E6: Pela mistura de alguma coisa na água.

E10: Sei que quando fizemos alguma experiência química se utilizamos alguma coisa na água de incolor passará a ter cor.

Dessa forma, inicialmente, nenhum estudante soube explicar corretamente essa questão, por meio dos aspectos científicos envolvidos. Porém, no questionário final, em que os estudantes foram investigados novamente sobre a presença de cor em soluções iônicas de metais de transição, a maioria conseguiu relacionar com a presença de elétrons nos orbitais $d$ parcialmente preenchidos, 1 estudante apenas não conseguiu explicar e outro confundiu e mencionou que a presença de cor era devido a ausência de elétrons nos orbitais $d$. Algumas respostas dos estudantes foram:

E5: Os orbitais d não podem estar preenchidos e nem vazios.

E10: O orbital deve estar parcialmente preenchido.

E12: Os orbitais d estão parcialmente preenchidos. 


\section{E13: Tem que ter orbital d e ser parcialmente completo.}

Com base na evolução das repostas dos estudantes no questionário final, consideramos que a realização da primeira atividade experimental, no terceiro momento da oficina temática, em que foram utilizadas diferentes soluções iônicas de metais de transição, bem como as explicações realizadas durante a oficina colaboraram de forma positiva no entendimento da presença de cor em algumas soluções iônicas de metais de transição.

\section{Considerações finais}

A oficina temática "A Química das Cores", foi importante para o desenvolvimento de conteúdos científicos. Isso foi evidenciado pelos resultados obtidos nessa pesquisa, pois inicialmente os estudantes apresentaram poucos conhecimentos relacionados à temática, e após o desenvolvimento das intervenções foi possível verificar uma evolução em termos dos conhecimentos científicos.

Além disso, a abordagem da temática cores, por meio da oficina temática, possibilitou relacionar além de conteúdos de Química, conteúdos de Física, devido à temática estudada ser interdisciplinar e depender de conceitos científicos de várias áreas da Ciência para sua compreensão.

Os resultados obtidos nos permitem afirmar que o ensino de Química pode ser favorecido com a utilização de diferentes estratégias metodológicas, como no caso, das oficinas temáticas. A oficina descrita neste trabalho auxiliou os estudantes na construção do conhecimento, sendo que a abordagem da temática cores possibilitou que os estudantes fizessem relações com o seu cotidiano.

\section{Referências}

BRAIBANTE, M. E. F.; PAZINATO, M. S. O Ensino de Química através de temáticas: contribuições do LAEQUI para a área. Revista Ciência e Natura. 2014; 36(2): 819-826.

DELIZOICOV, D.; ANGOTTI, A. J.; PERNAMBUCO, M. M. Ensino de Ciências Fundamentos e Métodos. $3^{\text {a }}$. ed. São Paulo: Cortez, 2009.

KRAISIG, A. R. A Temática "Cores" no Ensino de Química. [Dissertação]. Santa Maria: Universidade Federal de Santa Maria/UFSM; 2016. 204p.

LEITE, D. de O.; PRADO, R. J. Espectroscopia no infravermelho: uma apresentação para o Ensino Médio. Revista Brasileira de Ensino de Física. 2012; 34(18): 2504 - 2504-9.

MALDAMER, O. A.; SANTOS, L. P. Ensino de Química em foco. Ijuí: Ed. Unijuí, 2010.

MARCONDES, M. E. R. Proposições metodológicas para o Ensino de Química: Oficinas Temáticas para a Aprendizagem da Ciência e o Desenvolvimento da Cidadania. Revista em extensão. 2008; 7:67-77.

MORAES, R. Uma tempestade de luz: a compreensão possibilitada pela análise textual discursiva. Revista Ciência e Educação. 2003; 9(2):191-211.

MORAES, R.; GALIAZZI, M. C. Análise textual discursiva: Processo reconstrutivo de múltiplas faces. Revista Ciência e Educação. 2006; 12(1):116-128.

OLIVEIRA, J. R. S, de. Contribuições e abordagens das atividades experimentais no ensino de ciências: reunindo elementos para a prática docente. Acta Scientiae. 2010; 12(1):139-153.

PAZINATO, M. S. Alimentos: Uma Temática Geradora do Conhecimento Químico. [Dissertação]. Santa Maria: Universidade Federal de Santa Maria/UFSM; 2012.177p.

PAZINATO, M. S.; BRAIBANTE, M. E. F. Oficina temática Composição Química dos Alimentos: Uma possibilidade para o Ensino de Química. Química Nova na Escola. 2014; 36(4):289-296. 
SILVA, G. S.; BRAIBANTE, M. E.; BRAIBANTE, H. T. S.; PAZINATO, M. S.; TREVISAN, M. C. Oficina temática: uma proposta metodológica para o ensino do modelo atômico de Bohr. Ciência e Educação. 2014; 20(2):481-495.

SILVA, G. S. A abordagem do modelo atômico de Bohr através de atividades experimentais e de modelagem. [Dissertação]. Santa Maria: Universidade Federal de Santa Maria/UFSM; 2013.217p.

SUART, R. de C.; MARCONDES, M. E. R. Atividades experimentais investigativas: habilidades cognitivas manifestadas por alunos do Ensino Médio. In: XIV Encontro Nacional de Ensino de Química [internet]; 2008 Julho 21 24; Paraná, Brasil, 2008 [acesso em 02 de março de 2017]. Disponível em: http://www.quimica.ufpr.br/eduquim/eneq2008/. 